\title{
Future perspective for diagnosis in autoimmune diseases
}

\author{
LUIS E.C. ANDRADE \\ Divisão de Reumatologia, Universidade Federal de São Paulo, Escola de Medicina, Rua Botucatu, 740 \\ 04023-062 São Paulo, SP, Brasil \\ Manuscript received on July 16, 2008; accepted for publication on September 3, 2009; \\ presented by LUIZ R. TRAVASSOS
}

\begin{abstract}
Human beings have taken successive approaches for the understanding and management of diseases. Initially brewed in supernatural concepts and mystical procedures, a vigorous scientific approach has emerged on the grounds of fundamental disciplines such as anatomy, microbiology, biochemistry, physiology, immunology, pathology, and pharmacology. The resulting integrated knowledge contributed to the current classification of diseases and the way Medicine is carried out today. Despite considerable progress, this approach is rather insufficient when it comes to systemic inflammatory conditions, such as systemic lupus erythematosus, that covers clinical conditions ranging from mild pauci-symptomatic diseases to rapidly fatal conditions. The treatment for such conditions is often insufficient and novel approaches are needed for further progress in these areas of Medicine. A recent breakthrough has been achieved with respect to chronic auto-inflammatory syndromes, in which molecular dissection of underlying gene defects has provided directions for target-oriented therapy. Such approach may be amenable to application in systemic auto-immune diseases with the comprehension that such conditions may be the consequence of interaction of specific environmental stimuli and an array of several and interconnected gene polymorphisms. On the bulk of this transformation, the application of principles of pharmacogenetics may lead the way towards a progressively stronger personalized Medicine.
\end{abstract}

Key words: autoimmunity, pharmacogenetics, gene polymorphism, auto-inflammatory diseases, systemic lupus erythematosus, rheumatoid arthritis.

\section{HISTORICAL PERSPECTIVE IN DIAGNOSIS PARADIGM}

Since ancient times, human beings have struggled to provide help to those suffering from the diverse illnesses that affect mankind and other living beings. Primitive paradigms were mainly based on instinct, mysticism and supernatural approaches. Dance rituals and magic medicines were the answer that those early professionals provided to the sufferers. With the advent of the early founders of the contemporary medical science in the Mediterranean area, a rational, observational and ethical approach was progressively established. Accordingly, the diagnostic and therapeutic approaches were

In commemoration of the $75^{\text {th }}$ anniversary of Escola Paulista de Medicina/Universidade Federal de São Paulo. E-mail: luis.andrade@unifesp.br then modified towards more effective procedures, including recommendations related to life style and hygiene. However, still at those early times the prevalent theories for health and disease were largely based on beliefs, such as the miasmas and circulating humors (blood, phlegm, black and yellow bile). Therapeutic interventions included baths at special temperatures, boiling oil, ointments, bloodletting, suction cups, and so on (Lyons and Petruccelli 1978).

With the advent of Renascence and the rising of the contemporary scientific system, as we know it today, different fields in natural sciences started to contribute to a body of objective knowledge that ultimately led to the establishment of the medical practice as we know today. Anatomy, physiology, chemistry, microbiology, 
and other scientific fields contributed to the building of a new body of knowledge that progressively allowed the conception of novel medical paradigms that gradually would replace the old ones. Miasmas and circulating humors were not appropriate to the facts brought up by objective investigations in microbiology, anatomy, physiology, and the nascent clinical chemistry. The new concepts would re-shape the established nosology (disease classification system). The art of clinical examination would also change with the aim of providing clues that would guide physicians in classifying their patients according to the new nosologic classification system. Academic clinical practice would feed back this emerging nosologic classification system and vice-versa. In due time, patients were diagnosed in a classification system that included conditions such as bacterial pneumonia, left heart failure, acute hepatitis, diabetes mellitus, gouty arthritis, and so on.

It is common practice that the application of novel paradigms into practical activities lags behind the scientific advance pace. In fact, for a considerable period of time, many of the involved professionals are bound to reject the novel ideas or to under-estimate the magnitude of the coming changes. To illustrate this point, let us suppose that a regular physician from the $17^{\text {th }}$ century was to be confronted with a medical assessment of a fiction patient as of today (Table I). We can easily expect that this renascence mind would be confused with mixed feelings of wonder and suspicion.

\section{NOSOLOGIC CLASSIFICATION SYSTEM AS A FUNCTION OF SCIENTIFIC AND TECHNOLOGICAL PROGRESS}

Scientific paradigms, systematic classifications of phenomena, and technology operate in an interactive mode in which each one of these three elements influences the progress of the other two (Fig. 1). Advances occurring in any of these three elements are expected to influence the two other elements. New methodological tools allow a closer look at the natural phenomena, which may contribute to improve the classification of the system and eventually confirm or challenge the established scientific paradigm. Novel scientific paradigms push the development of appropriate technology and demand novel classification systems. Examples of this kind of virtuous loop can be found in the several revolutions in Physics paradigms along the last four centuries. The same is true for Biology and related areas, including Medicine.

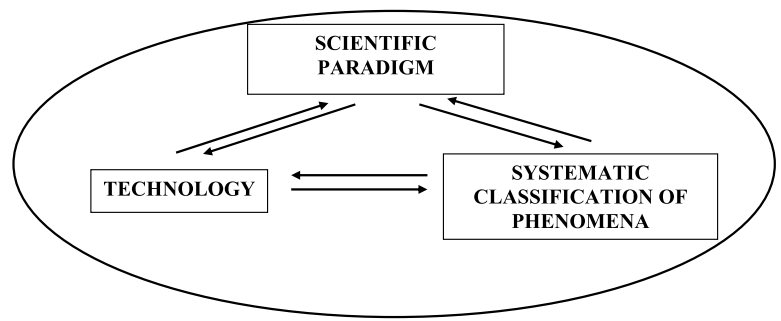

Fig. 1 - Mutual and virtuous interaction among scientific paradigms, technical advances, and classification systems.

\section{CRITICAL APPRAISAL OF THE CURRENT NOSOLOGY OF SYSTEMIC RHEUMATIC DISEASES}

The current nosologic classification of systemic rheumatic diseases has emerged in the middle of the $20^{\text {th }}$ century. During the first decades of the last century, the strong influence of Paul Erlich has pushed the scientific community towards the concept of "horror autotoxicus", which was erroneously understood as the impossibility of the immune system to recognize self-constituents. Systematic experimentation progressively disclosed, however, consistent evidence that, under certain circumstances, the immune system may set up a vigorous response against self tissues and organs. Some of these seminal experiments included the immunization of rabbits with thyroid tissue that elicited auto-reactive $\mathrm{T}$ lymphocytes and the destruction of the thyroid gland by an intense inflammatory infiltrate. In addition, the disease could be transferred to healthy animals by inoculation of lymphocytes from the immunized rabbits (Rose 1988, Doniach and Roitt 1988).

As a hint on how intense was the dispute in this field, one can evoke the episode in which the American hematologist William Harrington self injected plasma from a patient with putative immunologic thrombocytopenic purpura. After a few hours, the platelet count started falling down reaching a nadir of $7,000 / \mathrm{mm}^{3}$ coincident with an episode of generalized tonic-clonic convulsion. Fortunately, the devoted researcher recovered with no major sequel (Harrington et al. 1951).

On a clinical basis, two contemporary discoveries allowed the identification of serum factors with autoreactivity, namely the rheumatoid factor (Waller 1940) 
TABLE I

Fiction patient presented to a physician at the middle age era.

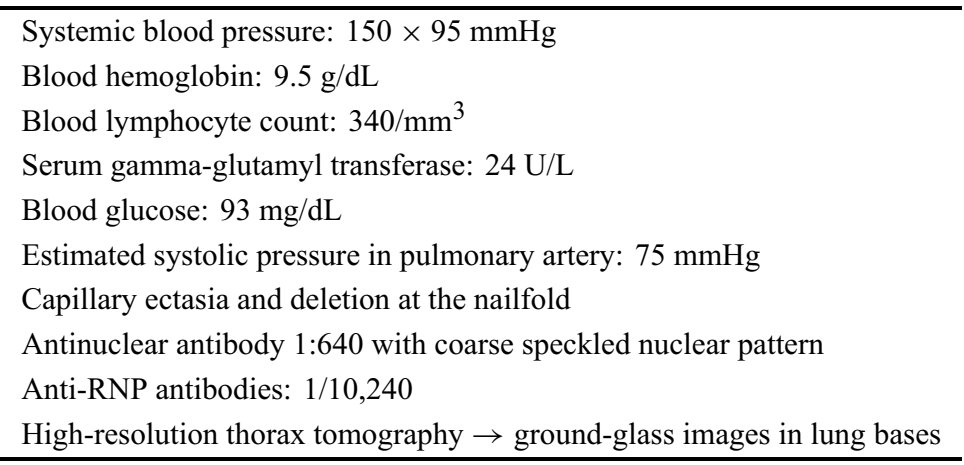

and the LE cell phenomenon (Hargraves et al. 1948). These two pioneer autoantibodies set the road for a vigorous research field that would flourish for the whole $20^{\text {th }}$ century (Tan 1997, Strassburg and Manns 2002, Sherer et al. 2004). The steady progress in the demonstration of a series of clinically relevant autoantibodies helped pave the way for the nosologic classification system for the new family of diseases, the so-called autoimmune diseases (Chan and Andrade 1992, Tan and Chan 1993, Dellavance et al. 2005).

Nowadays, the concept of autoimmunity is well established (Schwartz 1993). Diseases with widespread involvement are classified as non-organ specific autoimmune diseases. Examples of these include systemic lupus erythematosus (SLE), systemic sclerosis, dermatomyositis, polymyositis, rheumatoid arthritis, and Sjögren's syndrome. Those with a more restricted organ involvement are designated organ-specific autoimmune diseases. Examples of these are autoimmune thyroiditis, pemphigus vulgaris, myasthenia gravis, autoimmune hepatitis, and chronic biliary cirrhosis. Although this classification system has provided a reasonable framework to differentiate and manage these patients, it is not without flaws. In fact the extent to which a given disease is restricted to a certain organ is quite variable and many organ-specific autoimmune conditions present various degrees of systemic involvement. We can take autoimmune hepatitis type I as an example, in which skin and joint involvement is quite frequent (Manns and Vogel 2006). On the other hand, some of the non-organ specific autoimmune diseases frequently come into view as a quite restricted illness. A good example is Sjögren's syndrome, in which many patients show evidence of restricted involvement of salivary and lachrymal exocrine glands (Fox 2005, Barcellos et al. 2007). Rheumatoid arthritis and polymyositis are also frequently restricted to sinovial joints and skeletal muscles, respectively (Bouysset et al. 2005, Briani et al. 2006).

Another problematic point in the current classification system is that many patients present features that overlap two or more of the defined autoimmune diseases. It is not unusual, for example, that a patient with SLE presents isolated features suggestive of systemic sclerosis, such as swollen fingers, Raynaud's phenomenon, and esophageal dismotility (Furtado et al. 2002). In some cases, there is concomitant full-blown presentation of two or more of these conditions. The current classification system accommodates those cases as overlap syndromes (Rodriguez-Reyna and Alarcon-Segovia 2006). In addition, the association of an organ-specific and a non-organ specific disease is quite frequent. For example, patients with rheumatoid arthritis are frequently affected by thyroid autoimmune diseases (Somers et al. 2006).

However, the most crucial deficiency in the current autoimmune disease classification system is the failure in appropriately addressing the large heterogeneity within each nosologic entity. The diagnosis of SLE per se, for example, is not enough to provide an accurate idea of the prognosis of that particular patient or of what kind of treatment should be started. There is a wide clinical spectrum within this diagnostic label. Some patients will present a mild skin rash with arthralgia and occasional arthritis, will demand mild therapy, and will 
suffer no major impact on life style and no major interference with life perspectives. Some other patients with SLE may present serositis, thrombocytopenia, deforming skin involvement, and incapacitating fatigue. These may experience considerable interference with life style and professional and social performance. Finally, some other patients equally diagnosed as SLE may present severe and life-threatening manifestations, such as CNS vasculitis, alveolar hemorrhage or severe class IV glomerulonephritis. These few examples show clearly that it is not enough to say that a given patient has SLE. An accurate nosologic classification system should be able to narrow down the spectrum of manifestations expected for that diagnostic label and, therefore, allow for an accurate prediction of the disease course and the correspondent therapeutic planning for the patient (Fig. 2). Part of the complexity of disease phenotype is determined by non-genetic elements, such as environmental exposure, life style, quality of the medical care, compliance to the treatment, social and cultural level and existing co-morbidity. However, lessons from animal models and from clinical research have pointed that gene polymorphism also plays an important role in the determination of specific autoimmune phenotypes.
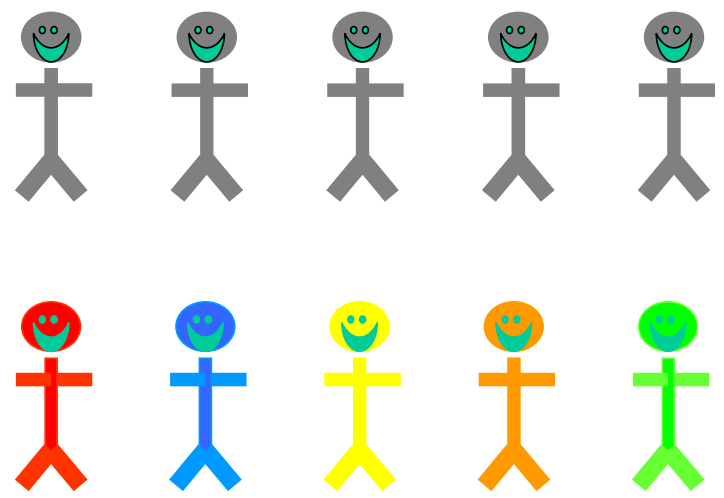

Fig. 2 - Unraveling well-defined sub-phenotypes underneath broadlabel general syndromes. Different patients with the label of a general syndrome (upper panel), like SLE for example, present specific clinical presentations with peculiar prognostic and therapeutic implications (lower panel).

Should the SLE entity be split into several other nosologic units? Should the SLE label be abandoned? What kind of novel nosologic entities should be defined? Could the same reasoning be appropriate for other au- toimmune diseases, such as rheumatoid arthritis, systemic sclerosis, polymyositis, and autoimmune liver diseases?

It seems that our contemporary body of knowledge and available technology are clearly not suitable for such a reformulation of the current autoimmune diseases classification system. However, one can always take the neighbor's experience as a perspective for one's own development. In fact, the case of the familial periodic fever syndromes, the so-called auto-inflammatory syndromes, may provide a clue to the diagnosis dissection needed for the field of autoimmune diseases.

\section{THE EXAMPLE OF THE AUTO-INFLAMMATORY SYNDROMES}

The recent development in the field of the hereditary auto-inflammatory syndromes is quite exciting. For many decades, the Mediterranean familial fever was the only form of hereditary periodic fever syndrome to be clinically and epidemiologically individualized. Over the past 10 years or so, other members of this family of conditions, now designated as auto-inflammatory syndromes, have been defined at the molecular level.

The hereditary periodic fever syndromes are characterized and defined by the following features: recurrent and self-limited episodes of fever and systemic inflammation with no apparent cause; variable involvement of skin, joints, serous membranes and internal organs; the presence of hereditary component; and the development of amyloidosis as a late complication (Grateau 2004). The prototypic and most common auto-inflammatory syndrome is Familial Mediterranean Fever. As suggested by the name, it affects predominantly subjects with descent from the Mediterranean area. It is an autosomal recessive condition caused by mutations in the $M E F V$ gene in region 16p13.3. Heterozygous subjects may present mild traits of the disease. The $M E F V$ gene codes for marenostrin, a protein that is able to modulate the effect of caspase 1 on the transcription regulation of IL- $1 \beta$ gene. Mutations in MEFV gene may cause a deficient inhibition of IL- $1 \beta$ expression and therefore induce a pro-inflammatory status (Zaks et al. 2003, Schaner and Gumucio 2005, Aróstegui et al. 2004).

Along the last decade, other idiopathic inflammatory syndromes have been demonstrated to fulfill the 
TABLE II

Molecular definition of auto-inflammatory syndromes.

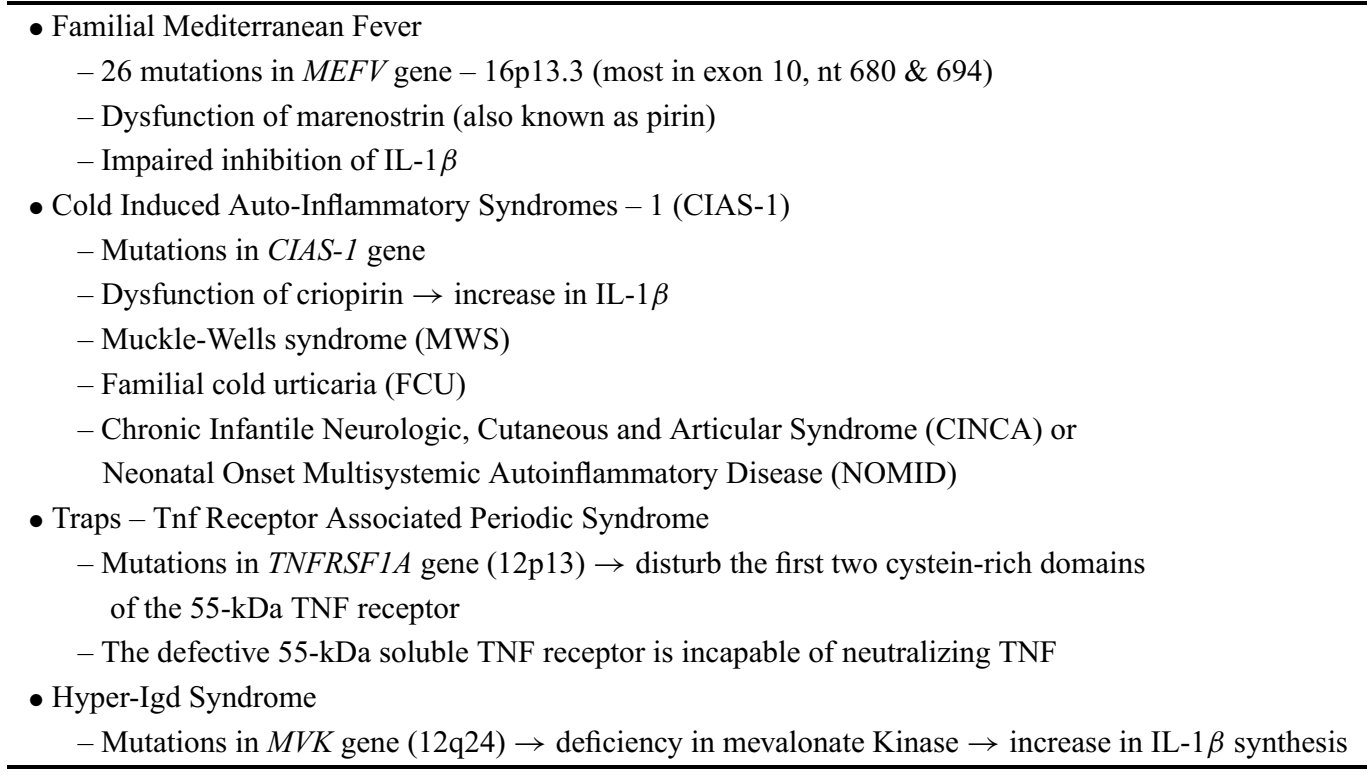

requirements for classification as auto-inflammatory syndromes and their underlying molecular defects have been identified. These include the Cold Induced Autoinflammatory Syndromes - 1 (CIAS-1) (Aróstegui et al. 2004), the TNF Receptor Associated Periodic Syndrome (TRAPS) (Masson et al. 2004, Aganna et al. 2003), and the Hyper-IgD syndrome (Prietsch et al. 2003). A preliminary list of molecular defects and mechanisms of the auto-inflammatory syndromes is depicted in Table II.

Would it be possible to adapt the molecular model of the auto-inflammatory syndromes to the classification of autoimmune diseases? The case of Autoimmune Lymphoproliferative Syndrome (ALPS) is quite compelling. This condition is characterized by adenomegaly, splenomegaly, autoimmune cytopenias, autoantibodies, and several SLE-like traits (reviewed in Worth et al. 2006). It is caused by mutations in genes involved in the Fas-mediated apoptosis pathway. Subtypes of ALPS with subtle clinical differences have been identified according to the specific molecular defect. Type Ia is caused by mutations in the TNFRSF6 gene (Fas - CD95); type $\mathrm{Ib}$ is associated with mutations in the TNFSF6 gene (Fas ligand or CD-95 ligand); type 2a is associated with mutations in the CASP10 gene (caspase 10); and type $2 \mathrm{~b}$ is caused by mutations in the CASP8 gene (caspase 8) (Worth et al. 2006. Although ALPS may offer a molecular definition for some cases labeled as SLE, it is clear that the vast majority of SLE patients have no defect in the Fas-mediated apoptosis pathway. However, other molecular mechanisms are long known to be associated with SLE, as is the case for congenital deficiency of early components of the complement system (C1q, C2, and C4) (Worth et al. 2006). Still, these represent a negligible fraction of SLE patients. Nonetheless, these examples are signaling that it may be possible to segregate specific clinical phenotypes within a vast and heterogeneous syndrome like SLE and to associate these novel relatively homogeneous clinical phenotypes with specific molecular defects. It has become progressively evident that the genetic regulation of autoimmune diseases is extremely complex, and that the establishment of an autoimmune status is conditioned by the interaction of several dozens of alleles. For the last 15 years, an increasing number of gene polymorphisms has been associated with susceptibility or specific clinical traits in several autoimmune diseases. In the case of SLE, for example, increased susceptibility has been associated with polymorphisms in the genes for IL-6, IL-10, Fc $\gamma$ RIIA, IIB, IIIA, IIIB, CLTA-4, PTPN22, Mannose 
binding lectin, angiotensin converting enzyme, DNase I, among others (Alarcon-Riquelme 2005).

It is relevant for the present issue that the importance of gene polymorphism is not restricted to the determination of disease susceptibility, but it has also been associated with disease phenotype in human and murine SLE (Nolsoe et al. 2005, Qi et al. 2005, Johansson et al. 2005). In that sense, gene polymorphism may indeed contribute to the dissection of a general syndrome like SLE into sub-phenotypes with distinct clinical, prognostic and therapeutic features. However, it is increasingly apparent that several gene polymorphisms must concert interactively to modulate each specific phenotype. Notwithstanding this complexity, it is possible that the most relevant genes involved in the determination of a given autoimmune phenotype would be eventually amenable to simultaneous analysis in some sort of multiplex platform. In fact, the challenge of a simultaneous and integrated analysis of multiple metabolic pathways is hard to be achieved with the standard research methodology. In this respect, the novel and powerful tools provided by large-scale methodological platforms may prove to be helpful.

\section{THE POTENTIAL CONTRIBUTION OF GENOMICS, TRANSCRIPTOMICS AND PROTEOMICS}

As opposed to the traditional approaches in biochemistry, microbiology, and immunology, the last two decades have brought large-scale methodologies that allow the simultaneous analysis of thousands of parameters in a single and even in multiple parallel biological specimens. As opposed to the traditional approach of addressing a single or a few analytes, these methodological platforms offer a comprehensive evaluation of hundreds or thousands of parameters that are collectively expressed as specific patterns associated with certain biological conditions. These complex patterns are sometimes referred to as biological signatures. The science of pattern recognition is long known and deals with the ability of identifying an object or situation by the comprehensive appreciation of the whole instead of the details (Bolinger and Ahlers 1975). This kind of ability is responsible for the recognition of a familiar face, voice or landscape in which the overall pattern is more decisive than each single parameter. Pattern recognition approach may be applied to the definition of healthy and diseased biological states. These large-scale methodologies have paved the way for the development of genomics, transcriptomics, and proteomics according to the kind of analyzed target, genomic DNA, messenger RNA, and proteins, respectively.

Although the term is relatively new, proteomics has been around for several decades. Classical Tiselius electrophoresis and polyacrylamide gel electrophoresis (PAGE), under reducing and non-reducing conditions, were the first means of discriminating proteins in a complex sample. The use of 2-dimensional electrophoresis increased the discrimination power to an order of hundreds or thousands. The use of antibodies as probes in western blotting and Protein A-Sepharose facilitated immunoprecipitation brought considerable specificity to this approach. More recently, the use of mass spectrometry coupled to matrix-assisted laser desorption/ionization time-of-flight (MALDI-TOF) has greatly increased the power of proteomics analysis (Buetow et al. 2001). As an example, the proteomic analysis of plasma may provide specific profiles for certain kinds of clinical conditions, such as early breast and prostate cancer (Ornstein et al. 2004, Martin 2006). A similar approach has been applied to the definition of proteomic signature of the inflammatory status in autoimmune conditions, such as SLE and Wegener's granulomatosis (Bennett et al. 2003, Stone et al. 2005).

Genomics has allowed for the sequencing of the genomes of hundreds of species, including the human species. Detailed maps have been elaborated for known genes, expressed sequence tags (ESTs), variable number tandem repeats (VNTR), and single nucleotide polymorphisms (SNPs). These maps are fundamental tools for linkage of the genetic information to disease susceptibility, disease phenotype, and pharmacogenetics (Belmont and Gibbs 2004). In parallel, the planar array technology has provided the possibility of probing one or more biological samples for hybridization with thousands of available sequences of the genome, thereby allowing the establishment of specific patterns for biological samples in terms of VNTR, SNPs, and other forms of gene polymorphism (Sosnowski et al. 2002, Frank 2002). This methodology has greatly enhanced our ability in determining polymorphism of a myriad of genes in a single 
assay. The impact of this methodology may be readily recognized by verifying the enormous number of publications on gene polymorphism of a great variety of genes in the last 10 years, as compared with the primary focus on polymorphism of the HLA system in the past decades.

The reverse transcription of sample messenger RNA into complementary DNA (cDNA) has made it possible to analyze the transcriptome, i.e., the gene expression pattern of a given biological sample. It is well appreciated that the full repertoire of genes of a given species is not used in each cell of the organism. In fact, only a certain assembly of genes is expressed in a given cell type and at a given physiologic status. The gene expression pattern of a given cell contributes to its specific phenotype. For instance, erythroid precursors synthesize hemoglobin and neurons synthesize neurotransmitters. As cells move from a physiologic to a pathologic status, the gene expression pattern and the protein expression profile change accordingly. The cDNA microarray technology has taken advantage of the gene expression pattern, to help distinguishing normal from tumoral tissue in lung, breast, stomach and other forms of cancer (Martin 2006, Brennan et al. 2005). Gene expression and protein profile are expected to be also useful in monitoring the therapeutic gene modulation in several conditions (Wulfkuhle et al. 2004). In SLE, microarray analysis of peripheral blood mononuclear cells has allowed the definition of a characteristic expression signature associated with genes regulated by Type I IFN, and this pattern is associated with disease activity (Belmont and Gibbs 2004). Proteomic analysis of biological samples has been also applied to the detection of several types of cancer (Ornstein et al. 2004, Liotta and Petricoin 2006) and to the assessment of the activity status of certain inflammatory diseases (Stone et al. 2005).

These novel tools have readily contributed to the understanding and managing of diseases associated with cancer and simple genetic syndromes. Applications of this methodology are emerging also for the field of autoimmune diseases. The determination of polymorphisms in genes for cytokines, chemokines, cell surface receptors, adhesion molecules, and downstream signaling molecules has been intensively analyzed in several autoimmune diseases with respect to disease susceptibility and disease phenotype (Table III).

\section{PHARMACOGENETICS - THE CASE FOR RHEUMATOID ARTHRITIS}

A particular application of gene polymorphism studies is the emerging field of pharmacogenetics or pharmacogenomics. This emerging and promising science is committed with the definition of how gene polymorphism may influence the several pharmacological aspects of a certain drug, including pharmacokinetics, pharmacodynamics, and side effects (Marsh and McLeod 2006, Eichelbaum et al. 2006). A large amount of studies has been dedicated to this kind of investigation, and several clinical applications are already available.

Several anti-depressants are metabolized by cytochrome P450 (CYP) enzymes in the liver. It has been demonstrated that polymorphism in CYP 2C19 and 2D6 is associated with the metabolic rate of venlafaxine, amitriptyline, and risperidone (Eichelbaum et al. 2006, van der Weide et al. 2005). Polymorphism in these genes has been shown to influence drastically the metabolic rate and therefore the effectiveness and toxicity of these drugs. Gene polymorphism influence on therapeutics has been also shown to be relevant to several other conditions, such as cancer, osteoporosis, essential hypertension, and dyslipidemias (Rodriguez-Antona and Ingelman-Sundberg 2006, Carbonell-Sala et al. 2005, Arnett et al. 2006, Schmitz and Langmann 2006).

Pharmacogenomics has been applied also to systemic autoimmune diseases. In fact, this field is rather complex and has great potential, as can be exemplified by studies carried on in rheumatoid arthritis. Methotrexate (MTX) has been largely used for this disease and has been shown to be effective in 46 to $65 \%$ of the cases (Bathon et al. 2000). Toxicity of MTX leading to discontinuation of treatment in RA varies from 10 to $30 \%$ (Alarcon et al. 1989). It is possible that gene polymorphism may be correlated to some extent with the effectiveness and toxicity of this drug in RA patients. MTX is a folate analog and acts as a competitive inhibitor of the enzyme dihydrofolate reductase (DHFR). Reduced folate carrier 1 (RFC-1) mediates MTX entry to cells. MTX efflux from the cell is mediated by the ATP-binding cassette (ABC) transporters (ABCC 1-4 and ABCG2). Intracellular MTX is converted into a polyglutamate form by the enzyme folylpolyglutamyl synthase (FPGS). The polyglutamate forms of MTX (MTXPG2-7) remain in- 
TABLE III

Gene polymorphism association with susceptibility and phenotype of autoimmune diseases.

\begin{tabular}{|c|c|c|}
\hline \multicolumn{3}{|c|}{ Association with susceptibility } \\
\hline Gene and allele & Clinical condition & Reference \\
\hline HLA-DQ2 \& DQ-8 & Celiac Disease & Lundin 2003 \\
\hline PTPN22 1858T & RA, SLE, GD, type 1 DM and JIA & Lee et al. 2007 \\
\hline DRB1*07 / CTLA-4 49G & Graves Disease & Kula et al 2006 \\
\hline GSTM1 null genotype & RA & Morinobu et al. 2006 \\
\hline CTLA $-4 * \mathrm{G}$ allele & type $1 \mathrm{DM}$ & Kavvoura and Ioannidis 2005 \\
\hline Desmoglein $1809 \mathrm{C}$ allele & Pemphigus foliaceus & Martel al. 2002 \\
\hline MBL HYPA haplotype & Primary biliary cirrhosis & Matsushita et al. 2001 \\
\hline \multicolumn{3}{|c|}{ Association with disease phenotype } \\
\hline Gene and allele & Clinical condition & Reference \\
\hline CTLA-4 +49A allele & Extra-glandular Sjögren's syndrome & Downie-Doyle et al. 2006 \\
\hline IL4 Receptor V50 allele & Erosive rheumatoid arthritis & Prots et al. 2006 \\
\hline FC $\gamma$ RIIIB (few copies) & Nephritis in SLE & Aitman et al. 2006 \\
\hline ACE D allele & Macrovascular disease in SSc & Guiducci et al. 2006 \\
\hline IL- $1 \alpha-889$ T allele & Lack of response to cyclophosphamide in SSc & Beretta et al. 2007 \\
\hline CCR5 59029G allele & Nephropathy in type $1 \mathrm{DM}$ & Mlynarski et al. 2005 \\
\hline
\end{tabular}

RA: rheumatoid arthritis; SLE: systemic lupus erythematosus; GD: Grave's disease; DM: diabetes mellitus; JIA: juvenile idiopathic arthritis; MBL: mannose binding lectin; ACE: angiotensin converting enzyme; SSc: systemic sclerosis.

side the cell and inhibit DHFR, which reduces dihydrofolate (DHF) to tetrahydrofolate (THF), and thereby affects the cellular folate pool. MTXPGs also inhibit thymidylate synthase (TYMS), which converts deoxyuridylate to deoxythymidylate in the de novo pyrimidine biosynthetic pathway (Dervieux et al. 2004a). Methylenetetrahydrofolate reductase (MTHFR) is indirectly inhibited by MTX, by means of the effects of MTX on the intracellular folate pool. MTX effect on the purine synthesis ultimately increases the intracellular adenosine pool, which is a potent anti-inflammatory agent. Potentially relevant gene polymorphisms refer to genes that influence MTX transport across cell membrane and those involved in intracellular MTX pathway. RFC-1 G80A polymorphism has been associated to the effectiveness of MTX uptaken by cells. Higher MTXPG levels have been reported in RA patients with the RFC $80 \mathrm{~A} / \mathrm{A}$ genotype as compared with those who had the RFC $80 \mathrm{G} / \mathrm{G}$ or $\mathrm{G} / \mathrm{A}$ genotypes $(\mathrm{P}<0.007)$ (Dervieux et al. 2004a). Accordingly, the G80A SNP has been positively associated with a better response to MTX in 105 patients with RA (Dervieux et al. 2004b). SNPs have been reported for several members of the ABC family of transporters, some of which are involved in MTX efflux from the intracellular compartment. A recent study on the $\mathrm{ABCB} 1$ gene has found that patients with the $3435 \mathrm{CC}$ and $3435 \mathrm{CT}$ genotypes had a greater risk of having active RA compared with patients with the 3435TT genotype. The $3435 \mathrm{~T}$ allele also seemed to confer a protective effect, with patients homozygous for this allele having a less severe form of RA that was more likely to respond to MTX and prednisone (Pawlik et al. 2004). Genetic variations in other members of the $\mathrm{ABC}$ family are quite common and shall be explored in the context of RA and MTX treatment.

The metilenetetrahidrofolate reductase (MTHFR) is the best studied of the genes in the MTX cellular pathway. MTHFR is important in the generation of 5-methyl-THF, which is the methyl donor for the methylation of homocysteine to methionine by methionine synthase (MS). Among several others, two non-synonymous SNPs have been extensively studied. The C677T polymorphism is 
associated with homocystein plasma concentration and seems to be associated with MTX toxicity, especially with hepatotoxicity. On the other hand, the A1298C polymorphism seems to have no effect on MTX toxicity, but seems to be associated with MTX efficacy in RA patients (Urano et al. 2002).

Thymidilate synthase (TYMS) is a key enzyme in the de novo thymidylate synthesis (conversion of dUMP into dTMP). TYMS is inhibited directly by MTXPGs and indirectly by the folate cofactor depletion induced by MTX. Two relevant TYMS polymorphisms have been studied with respect to MTX in RA patients. A polymorphic tandem repeat sequence in the 5'-untranslated region (5'-UTR) correlates with TYMS mRNA expression. Patients homozygous for the triple repeat allele (TSER*3/*3) have higher TYMS mRNA expression than those homozygous for a double repeat allele (TSER*2/ *2). Another relevant polymorphism consists of a 6-bp deletion of the sequence TTAAAG at nucleotide 1494 in the 3'-UTR (3'-UTR 6-bp deletion). Apparently the 3'UTR deletion is associated with decreased TYMS mRNA stability and expression. Preliminary evidence suggests that the TSER $* 3 / * 3$ polymorphism (increased TYMS expression) lowered MTX efficacy and the 3'-UTR 6bp deletion (decreased TYMS expression) made RA patients more sensitive to MTX (Kumagai et al. 2003).

Several other genes may affect MTX efficacy and toxicity, including AMP-activated protein kinase activator (AICAR), transformylase, $\gamma$-glutamyl hydrolase (GGH), dihydrofolate reductase (DHFR), methionine synthase (MS), methionine synthase reductase (MTRR) and serine hydroxymethyltransferase (SHMT). Eventually, the concomitant analysis of the polymorphism in several of these genes will provide an appropriate estimate of the expected therapeutic effect and toxicity of MTX in a given RA patient (Dervieux et al. 2004b).

Tumor necrosis factor (TNF) antagonists have been shown to be a rather effective therapeutic alternative for some patients with RA, Crohn's disease, psoriatic arthritis and ankylosing spondylitis. However, only up to $60 \%$ of the patients will present a satisfactory response to antiTNF therapy. There is a functional bi-allelic polymorphism in the TNF- $\alpha$ gene A-308G, in which the A allele is associated with greater expression of the TNF gene. Preliminary results have suggested that the G/G pheno- type is associated with a good response, the A/G phenotype is associated with a moderate response, and the $\mathrm{A} / \mathrm{A}$ phenotype is associated with therapeutic failure (Seitz et al. 2007). Although not all investigators have achieved this clear-cut association, it seems to be a prevalent trend among most of the studies (Ranganathan 2005).

These few examples are representative of the general trend that is quickly expanding to encompass the several therapeutic agents and pathological conditions within and outside the field of autoimmunity.

\section{PERSPECTIVES PROVIDED BY NOVEL TECHNIQUES - THERANOSTICS}

The perspectives provided by the novel available technologies appear to promise a real revolution not only in diagnostic procedures, but also in the current paradigm for Medicine itself. The nosologic classification system as we know it today may be totally reshaped in some areas of Medicine. Some fields will not undergo radical changes. For example, a patient with inguinal hernia will probably have the same diagnosis as today. In contrast, the vague diagnosis of SLE may change drastically. It may happen that we will not even talk of SLE in the future. Specific immunologic imbalances conditioned by peculiar sets of gene polymorphisms and characterized by defined patterns of immune mediators expression may be identified within the broad family of patients nowadays diagnosed as SLE. Each one of these molecularly defined SLE subsets shall be associated with a peculiar clinical picture and prognosis. Accordingly, the appropriate therapy will be individualized for each one of these novel molecular-defined nosologic entities. Eventually, it is possible that efforts will be addressed to the individual molecular imbalances of each patient as opposed to the current efforts to classify patients into pre-defined general nosologic categories. This trend has been clearly announced as the Individualized Medicine.

On the top of that, pharmacogenetics will provide an additional degree of individualization for therapy. Once the molecular imbalance is defined and the corrective therapeutics is devised, the physician will probably need to confront the therapeutic options with the patient gene data bank containing the drug-relevant gene polymorphisms for that specific patient. As discussed above, 
TABLE IV

Fiction patient in year 2097.

- Disequilibrium Th1/Th2 in peripheral blood $\rightarrow 65 \%$

- Depressed proportion of Treg in peripheral blood $\rightarrow 0.5 \%$

- DRB1 gene polymorphism $\rightarrow$ presence of single copy of *0404 allele

- MBL gene heterozigosity $\rightarrow$ presence of alleles A and D

- TNF- $\alpha$ gene promoter polymorphism at $-308 \rightarrow$ allele $-308 \mathrm{~A}$ in double copy

- Homozygosity for allele $131 \mathrm{R}$ in Fc $\gamma$ RII gene

- Protein tyrosine phosphatase non-receptor 22 (PTPN22) $\rightarrow$ single copy of 1858 T allele

- Decreased Thymus Recent-Emigrant T cells $\rightarrow 15,4678$ TREC copies/ $\mu$ g CD4 $\oplus$ DNA

- Hyperexpression of IL-17, IL-2 and osteoprotegerin

- Acceleration in IFN- $\gamma$-induced gene activation sequence in macrophages

for some applications it is already feasible to assess how polymorphism of individual genes influences the therapeutic response to certain drugs. It is quite possible that the molecular definition of disease condition and therapeutics on an individual basis will occur concomitantly in an interactive fashion. This trend has been termed Theranostics and may dominate the management of patients in the future (Picard and Bergeron 2002, Jain 2002).

\section{MEDICINE IN YEAR 2097}

It seems not risky to forecast that Medicine will change drastically in the coming decades. Many of the clinical entities, diagnostic procedures, and therapeutic options of today shall disappear. Novel paradigms, the emerging technology, and the evolving clinical practice shall re-shape each other towards a more individualized Medicine. In a provocative scenario, one can foresee the clinical workout of a patient in year 2097 (Table IV). This may cause wonder and skepticism to some of us nowadays in the same way that our current medical approach would have caused if shown to a 1597's physician (Table I). This historical perspective is reassuring in that it lends credibility to the viability of an accomplishing future for Medicine. However, a word of caution must be said with respect to the economical impact of the current and evolving health care. The constant progress in medical diagnosis and treatment has generated genuine cost inflation in the health care system and has imposed difficult challenges for health care managers all over the world. Therefore the novel technologies towards individualized Medicine need to be- come economically feasible in order to thrive.

\section{RESUMO}

O homem tem buscado sucessivas abordagens para o entendimento e manejo das doenças. Partindo de conceitos sobrenaturais e procedimentos místicos, uma abordagem científica vigorosa vicejou com base em disciplinas fundamentais como a anatomia, microbiologia, bioquímica, fisiologia, imunologia, patologia e farmacologia. O conhecimento integrado resultante contribuiu para a atual classificação das doenças e a forma com que a Medicina atual é praticada. Apesar deste considerável progresso, esta abordagem é insuficiente quando se trata de condições inflamatórias sistêmicas, como o lúpus eritematoso sistêmico, que abrange condições variando de formas brandas e pauci-sintomáticas até condições rapidamente fatais. O tratamento dessas condições é frequentemente insuficiente e novas abordagens são necessárias para progresso adicional nessas áreas da Medicina. Um avanço recente foi obtido no que tange às síndromes auto-inflamatórias hereditárias, nas quais a dissecção molecular dos defeitos gênicos subjacentes forneceu direcionamento para terapia orientada a alvos moleculares específicos. Esta abordagem é passível de aplicação às doenças auto-imunes sistêmicas com a compreensão de essas condições podem ser conseqüência da interação de estímulos ambientais específicos e uma gama de vários polimorfismos gênicos interconectados. No escopo dessa transformação, a aplicação dos princípios de farmacogenéticas poderá contribuir para o progressivo desenvolvimento de uma Medicina personalizada vigorosa.

Palavras-chave: auto-imunidade, farmacogenética, polimorfismo gênico, síndromes auto-inflamatórias, lúpus eritematoso sistêmico, artrite reumatóide. 


\section{REFERENCES}

AgAnNA E ET AL. 2003. Heterogeneity among patients with tumor necrosis factor receptor-associated periodic syndrome phenotypes. Arthritis Rheum 48: 2632-2644.

Aitman TJ ET AL. 2006. Copy number polymorphism in Fcgr3 predisposes to glomerulonephritis in rats and humans. Nature 439 (7078): 851-855.

Alarcon GS, TraCY IC AND BlaCKBURN WD JR. 1989. Methotrexate in rheumatoid arthritis: toxic effects as the major factor in limiting long-term treatment. Arthritis Rheum 32: 671-676.

ALARCON-RIQUELME ME. 2005. The genetics of systemic lupus erythematosus. J Autoimmun 25: 46-48.

Arnett DK, ClaAs SA And Glasser SP. 2006. Pharmacogenetics of antihypertensive treatment. Vascul Pharmacol 44: 107-118.

Aróstegui JI ET AL. 2004. Clinical and genetic heterogeneity among spanish patients with recurrent autoinflammatory syndromes associated with the CIAS1/PYPAF1/ NALP3 gene. Arthritis Rheum 50: 4045-4050.

Barcellos KS, Nonogaki S, ENOKIHARA MM, TEIXEIRA MS AND ANDRADE LE. 2007. Differential Expression of Ro/SSA $60 \mathrm{kDa}$ and La/SSB, but not Ro/SSA $52 \mathrm{kDa}, \mathrm{mRNA}$ and Protein in Minor Salivary Glands from Patients with Primary Sjogren's Syndrome. J Rheumatol 34: 1283-1292.

BATHON JM ET AL. 2000. A comparison of etanercept and methotrexate in patients with early rheumatoid arthritis. N Engl J Med 343: 1586-1593.

Belmont JW And GiBBs RA. 2004. Genome-wide linkage disequilibrium and haplotype maps. Am J Pharmacogenomics 4: 253-262.

Bennett L, Palucka AK, Arce E, Cantrell V, BorVAK J, BAnchereau J And Pascual V. 2003. Interferon and granulopoiesis signatures in systemic lupus erythematosus blood. J Exp Med 197: 711-723.

Beretta L, CAppiello F, BARili M, Bertolotti F AND SCORZA R. 2007. T-889C IL-1 alpha promoter polymorphism influences the response to oral cyclophosphamide in scleroderma patients with alveolitis. Clin Rheumatol 26: 88-91.

Bolinger RE AND AHLERs P. 1975. The science of "pattern recognition”. JAMA 233: 1289-1290.

Bouysset M, Noel E And TebiB JG. 2005. Rheumatoid arthritis: a general disease and local diseases. Rev Prat 55: 2121-2133.
Brennan DJ, O'Brien SL, Fagan A, Culhane AC, Higgins DG, Duffy MJ AND Gallagher WM. 2005. Application of DNA microarray technology in determining breast cancer prognosis and therapeutic response. Expert Opin Biol Ther 5: 1069-1083.

Briani C, Doria A, SARzi-Puttini P And DAlakas MC. 2006. Update on idiopathic inflammatory myopathies. Autoimmunity 39: 161-170.

BuEtow KH ET AL. 2001. High-throughput development and characterization of a genomewide collection of genebased single nucleotide polymorphism markers by chipbased matrix-assisted laser desorption/ionization time-offlight mass spectrometry. Proc Natl Acad Sci USA 98: $581-584$

Carbonell-Sala S, Masi L, Marini F, del Monte F, FAlChETTI A, FRANCESCHELli F AND BRANDI ML. 2005. Genetics and pharmacogenetics of osteoporosis. J Endocrinol Invest 28 (10 Suppl): 2-7.

CHAN EKL AND ANDRADE LEC. 1992. Antinuclear antibodies in Sjögren's syndrome. Rheum Dis Clin North Am 18: 551-569.

Dellavance A ET AL. 2005. The Clinical Spectrum of Antinuclear Antibodies Associated with the Nuclear Dense Fine Speckled Immunofluorescence Pattern. J Rheumatol 32: 2144-2149.

Dervieux T, Furst D, Lein DO, Capps R, Smith K, WAlsh M AND Kremmer J. 2004a. Polyglutamation of methotrexate with common polymorphisms in reduced folate carrier, aminoimidazole carboxamide ribonucleotide transformylase, and thymidylate synthase are associated with methotrexate effects in rheumatoid arthritis. Arthritis Rheum 50: 2766-2774.

Dervieux T, Kremer J, Lein DO, CApps R, BARHAM R, Meyer G, Smith K, Caldwell J And Furst DE. 2004b. Contribution of common polymorphisms in reduced folate carrier and glutamylhydrolase to methotrexate polyglutamate levels in patients with rheumatoid arthritis. Pharmacogenetics 14: 733-739.

DONIACH D AND ROITT IM. 1988. Human organ specific autoimmunity: personal memories. Autoimmunity 1: 1113.

Downie-Doyle S, BAyAT N, Rischmueller M AND LESTER S. 2006. Influence of CTLA4 haplotypes on susceptibility and some extraglandular manifestations in primary Sjogren's syndrome. Arthritis Rheum 54: 2434 2440 .

EICHELBAUM M, INGELMAN-SUNDBERG M AND EVANS 
WE. 2006. Pharmacogenomics and individualized drug therapy. Annu Rev Med 57: 119-137.

FOX RI. 2005. Sjogren's syndrome. Lancet 366: 321-331.

FRANK R. 2002. High-density synthetic peptide microarrays: emerging tools for functional genomics and proteomics. Comb Chem High Throughput Screen 5: 429-440.

Furtado RNV, Pucinelli MLC, Cristo VV, ANDRAdE LEC AND SATO EI. 2002. Scleroderma-like nailfold capillaroscopic abnormalities are associated with anti-U1RNP antibodies and Raynaud's phenomenon in SLE patients. Lupus 11: 35-41.

GrateAu G. 2004. Clinical and genetic aspects of the hereditary periodic fever syndromes. Rheumatology 43: 410415.

Guiducci S, Fatini C, Rogai V, Cinelli M, Sticchi E, AbBate R And Cerinic MM. 2006. Angiotensinconverting enzyme in systemic sclerosis: from endothelial injury to a genetic polymorphism. Ann N Y Acad Sci 1069: 10-19.

HARGRAVES MM, RichMOND H AND MORTON R. 1948. Presentation of two bone marrow elements: the "tart" cell and the "LE" cell. Mayo Clin Proc 23: 25-28.

Harrington WJ, Minnich V, Hollingsworth JW AND MOORE CV. 1951. Demonstration of a thrombocytopenic factor in the blood of patients with thrombocytopenic purpura. J Lab Clin Med 38: 1-10.

JAIN KK. 2002. Personalized medicine. Curr Opin Mol Ther 4: 548-558.

Johansson M, ARlestig L, Moller B And RANTAPAADAHLQVIST S. 2005. Association of a PDCD1 polymorphism with renal manifestations in systemic lupus erythematosus. Arthritis Rheum 52: 1665-1669.

KAVVOURA FK AND IOANNIDIS JP. 2005. CTLA-4 gene polymorphisms and susceptibility to type 1 diabetes mellitus: a HuGE Review and meta-analysis. Am J Epidemiol 162: 3-16.

KULA D ET AL. 2006. Interaction of HLA-DRB1 alleles with CTLA-4 in the predisposition to Graves' disease: the impact of DRB $1 * 07$. Thyroid 16: 447-453.

Kumagai K, Hiyama K, Oyama T, Maeda H and Kohno N. 2003. Polymorphisms in the thymidylate synthase and methylenetetrahydrofolate reductase genes and sensitivity to the low-dose methotrexate therapy in patients with rheumatoid arthritis. Intl J Mol Med 11: 593-600.

Lee YH, Rho YH, Choi SJ, Ji JD, Song GG, NATh SK AND HARleY JB. 2007. The PTPN22 C1858T func- tional polymorphism and autoimmune diseases - a metaanalysis. Rheumatology (Oxford) 46: 49-56.

Liotta LA And Petricoin EF. 2006. Serum peptidome for cancer detection: spinning biologic trash into diagnostic gold. J Clin Invest 116: 26-30.

LUNDIN KE. 2003. HLA-DQ8 as an Ir gene in coeliac disease. Gut 52: 7-8.

Lyons AS AND Petrucelli RJ. 1978. Medicine - An illustrated history. HN Abrams Inc Publishers, New York, n. 289.

Manns MP And Vogel A. 2006. Autoimmune hepatitis, from mechanisms to therapy. Hepatology 43 (2 Suppl 1): S132-144.

Marsh S AND MCLeOd HL. 2006. Pharmacogenomics: from bedside to clinical practice. Hum Mol Genet Spec 1: R89-93.

Martel P, Gilbert D, Busson M, Loiseau P, Lepage V AND Drouot L. 2002. Epistasis between DSG1 and HLA class II genes in pemphigus foliaceus. Genes Immun 3: 205-210.

Martin M. 2006. Molecular biology of breast cancer. Clin Transl Oncol 8: 7-14.

Masson C, Simon V, Hoppé E, Insalaco P, Cissé I AND AUdRAn M. 2004. Tumor necrosis factor receptorassociated periodic syndrome (TRAPS): definition, semiology, prognosis, pathogenesis, treatment, and place relative to other periodic joint diseases. Joint Bone Spine 71: 284-290.

Matsushita M, MiYakawa H, Tanaka A, HiJikata M, KIKUCHI K AND FUJiKaWA H. 2001. Single nucleotide polymorphisms of the mannose-binding lectin are associated with susceptibility to primary biliary cirrhosis. J Autoimmun 17: 251-257.

MLynarski WM, Placha GP, Wolkow PP, BochenSKI JP, WARRAM JH AND KROLEWSKI AS. 2005. Risk of diabetic nephropathy in type 1 diabetes is associated with functional polymorphisms in RANTES receptor gene (CCR5): a sex-specific effect. Diabetes 54: 3331-3335.

Morinobu S, Morinobu A, Kanagawa S, Hayashi N, Nishimura K AND KUMAGAi S. 2006. Glutathione S-transferase gene polymorphisms in Japanese patients with rheumatoid arthritis. Clin Exp Rheumatol 24: 268-273.

Nolsoe Rl, Kelly JA, Pociot F, Moser KL, KrisTIANSEN OP, MANDRUP-POULSEN T AND HARLEY JB. 2005. Functional promoter haplotypes of the human FAS gene are associated with the phenotype of 
SLE characterized by thrombocytopenia. Genes Immun 6: 699-706.

ORNSTEIN DK, RAYFORD W, FusARO VA, CONRADS TP, Ross SJ, Hitt BA, Wiggins WW, Veenstra TD, Liotta LA AND Petricoin EF3Rd. 2004. Serum proteomic profiling can discriminate prostate cancer from benign prostates in men with total prostate specific antigen levels between 2.5 and $15.0 \mathrm{ng} / \mathrm{ml}$. J Urol 172: 13021305.

PAWLIK A, WRZESNIEWSKA J, FIEDOROWICZ-FABRYCY I AND GAWRONSKA-SZKLARZ B. 2004. The MDR1 3435 polymorphism in patients with rheumatoid arthritis. Intl J Clin Pharmacol Ther 42: 496-503.

PiCARD FJ AND BERGERON MG. 2002. Rapid molecular theranostics in infectious diseases. Drug Discov Today 7: 1092-1101.

Prietsch V, Mayatepek E, Krastel H, HaAs D, ZunDEL D, WATERHAM HR, WANDERS RJ, Gibson KM AND HofFMAnN GF. 2003. Mevalonate kinase deficiency: enlarging the clinical and biochemical spectrum. Pediatrics 111: 258-261.

PROTS I ET AL. 2006. Association of the IL4R singlenucleotide polymorphism $\mathrm{I} 50 \mathrm{~V}$ with rapidly erosive rheumatoid arthritis. Arthritis Rheum 54: 1491-1500.

Qi ZM, WANG J, SUn ZR, MA FM, Zhang QR, Hirose S AND JIANG Y. 2005. Polymorphism of the mouse gene for the interleukin 10 receptor alpha chain (I110ra) and its association with the autoimmune phenotype. Immunogenetics 57: 697-702.

RANGANATHAN P. 2005. Pharmacogenomics of tumor necrosis factor antagonists in rheumatoid arthritis. Pharmacogenomics 6: 481-490.

Rodriguez-Antona C AND IngELMAn-Sundberg M. 2006. Cytochrome P450 pharmacogenetics and cancer. Oncogene 25: 1679-1691.

RodrigueZ-REYNA TS AND AlarCON-SEgovia D. 2006. The different faces of shared autoimmunity. Autoimmun Rev 5: 86-88.

Rose NR. 1988. Autoimmunity: a personal memoir. Autoimmunity 1: 15-21.

SCHANER PE AND GUMUCIO DL. 2005. Familial Mediterranean fever in the post-genomic era: how an ancient disease is providing new insights into inflammatory pathways. Curr Drug Targets Inflamm Allergy 4: 67-76.

Schmitz G AND LANGMAnN T. 2006. Pharmacogenomics of cholesterol-lowering therapy Vascul Pharmacol 44: $75-89$.
SCHWARTZ RS. 1993. Autoimmunity and autoimmune diseases. In PAUL WE: Fundamental Immunology $3^{\text {rd }}$ ed., Raven Press, New York, p. 1033-1089.

Seitz M, Wirthmuller U, Moller B and Villiger PM. 2007. The -308 tumour necrosis factor- $\alpha$ gene polymorphism predicts therapeutic response to TNF $\alpha$-blockers in rheumatoid arthritis and spondyloarthritis patients. Rheumatology (Oxford) 46: 93-96.

Sherer Y, Gorstein A, Fritzler MJ ANd Shoenfeld Y. 2004. Autoantibody Explosion in Systemic Lupus Erythematosus: More than 100 Different Antibodies Found in SLE Patients. Semin Arthritis Rheum 34: 501-537.

Somers EC, Thomas SL, Smeeth L and Hall AJ. 2006. Autoimmune diseases co-occurring within individuals and within families: a systematic review. Epidemiology 17: 202-217.

Sosnowski R, Heller MJ, Tu E, Forster AH AND RADTKEY R. 2002. Active microelectronic array system for DNA hybridization, genotyping and pharmacogenomic applications. Psychiatr Genet 12: 181-192.

STONE JH ET AL. 2005. A serum proteomic approach to gauging the state of remission in Wegener's granulomatosis. Arthritis Rheum 52: 902-910.

Strassburg CP AND MANNS MP. 2002. Autoantibodies and autoantigens in autoimmune hepatitis. Semin Liver Dis 22: 339-352.

TAN EM. 1997. Autoantibodies and autoimmunity: a threedecade perspective. A tribute to Henry G. Kunkel. Ann N Y Acad Sci 815: 1-14.

TAN EM AND CHAN EK. 1993. Molecular biology of autoantigens and new insights into autoimmunity. Clin Invest 71: 327-330.

Urano W, Taniguchi A, Yamanaka H, Tanaka E, NaKaJima H, Matsuda Y, AKama H, Kitamura Y AND KAMATANi N. 2002. Polymorphisms in the methylenetetrahydrofolate reductase gene were associated with both the efficacy and the toxicity of methotrexate used for the treatment of rheumatoid arthritis, as evidenced by single locus and haplotype analyses. Pharmacogenetics 12: $183-190$.

VAN DER WEIDE J, VAN BAALEN-BENEDEK EH AND Kootstra-Ros JE. 2005. Metabolic ratios of psychotropics as indication of cytochrome P450 2D6/2C19 genotype. Ther Drug Monit 27: 478-483.

WALLER E. 1940. On the occurrence of a factor in human serum activating the specific agglutination of sheep blood corpuscles. Acta Pathol Microbiol Scand 17: 172-188. 
Worth A, Thrasher AJ And Gaspar HB. 2006. Autoimmune lymphoproliferative syndrome: molecular basis of disease and clinical phenotype. Br J Haematol 133: 124-140.

Wulfkuhle J, Espina V, Liotta L and Petricoin E. 2004. Genomic and proteomic technologies for individualisation and improvement of cancer treatment. Eur $\mathrm{J}$ Cancer 40: 2623-2632.
Zaks N, Shinar Y, Padeh S, Lidar M, Mor A, Tokov I, Pras M, Langevitz P, Pras E and Livneh A. 2003. Analysis of the three most common MEFV mutations in 412 patients with familial Mediterranean fever. Isr Med Assoc J 5: 585-588. 